\title{
Teaching Reform of Mechanic Vibration Based on Flipped Classroom and Constructivism
}

\author{
Liu Xiaobo \\ School of Aeronautical Manufacturing Engineering \\ Nanchang Hangkong University \\ Nanchang, China \\ liuxb2000@sina.com
}

\author{
Xiong Zhen \\ School of Aeronautical Manufacturing Engineering \\ Nanchang Hangkong University \\ Nanchang, China \\ 475380803@qq.com
}

\begin{abstract}
In order to solve the problems in the traditional teaching activities of mechanic vibration, a teaching reform is performed for mechanical engineering major students on the basis of in-depth understanding of constructivism and flipped classroom. The course content is integrated effectively by using flipped classroom and scaffolding instruction. The essential part and application sections of the course are carried out through flipped classroom combined random access instruction and anchored instruction, respectively. Practice proves that the teaching reform emphasizes the studentscentered conception, which is important to develop students' synthesize ability and the cultivation of innovative and entrepreneurial capacity.
\end{abstract}

Keywords-Constructivism; Flipped classroom; Mechanic vibration; Teaching reform

\section{INTRODUCTION}

"Mechanic vibration" is an important professional basic course for mechanical graduate students in institute of aeronautical manufacturing engineering, Nanchang Hangkong University. With the continuous improvement of the machine productivity as well as increase of the speed and acceleration of the load, mechanical dynamics problem has become increasingly prominent, including mechanic vibration as an important component of mechanical dynamics. This course is to adapt to the actual needs of production, the application of advanced mathematics, linear algebra, signal analysis, computer technology and other disciplines, from the practical point of view of the theory of mechanic vibration to discuss the theory, so that students can master the basic theory, and can abstract the actual machinery in the engineering as a mechanical model, and then use the existing knowledge on the basis of the correct mechanics to carry out the correct mechanical analysis to solve the practical problems. Cultivate students' comprehensive utilization of the knowledge they have learned to find problems and solve problems. However, in the actual teaching, this course is a typical "teacher difficult to teach, students difficult to learn" course. Since this course has more content, less class hour, complex concept, theoretical abstraction, and higher difficulty, therefore students are prone to boredom. Moreover, the teacher-centered, teaching materials as the center and the classroom as the center of the traditional teaching model is difficult to mobilize the enthusiasm and autonomy of students to learn, let alone cultivate innovation [1]

Based on the characteristics of curriculum and students, this paper focuses on "student-centered", guided by constructivism learning theory, with the flipped classroom as the main teaching method, the combination of Scaffolding Instruction, Random Access Instruction and Anchored Instruction teaching mode. Teaching reform inspired students from different angles to master the basic knowledge of mechanic vibration step by step, and gradually grasp the thinking ability and application ability needed to abstract the mechanical model from the actual problem. After more than a year of reform, the methods stimulated students' interest in learning, improved students' learning enthusiasm, cultivated students' ability to analyze and solve problems, and cultivated the students' creative and enterprise ability.

\section{FliPPED ClASSROOM AND CONSTRUCTIVISM TEACHING MODE}

In view of the many drawbacks of traditional teaching, constructivism learning theory has made a new explanation for learning and teaching [2-3]. Flipped classroom teaching method extends the teaching time and space, students can arrange their time to watch MOOC, SPOC or videos and other information provided by teacher, students discuss with teacher in the class to get a deeper understanding of knowledge [4-5] The "Mechanic vibration" curriculum has the characteristics of "three strong", that is, strong theoretical, strong abstract and strong practical application. It can not achieve good teaching results if constructivism teaching mode or flip classroom teaching methods are simply used.

Constructivism learning theory and flipped classroom have some commonalities between learning concept and teaching concept [6]. Based on the reality of teaching design, it is necessary to comprehensively apply the content of multiple courses (or even disciplines) from multiple perspectives to analyze the problem; it has the characteristics of comprehensiveness and openness. In order to finish a certain "Meaning Construction" within the limited class hours, students need to consult a large amount of materials under the premise of earnestly studying the materials provided by teachers before class or after class, and actively carry out or 
participate in various forms of learning and discussion activities to save some time for class discussion and teacher' explanation.

\section{TeAChING Design BASED ON FLIPPED ClASSROOM AND CONSTRUCTIVISM}

Common constructivism teaching methods are divided into scaffolding teaching anchored teaching and random entry teaching. The whole idea of curriculum reform is under the guidance of constructivism learning theory, to flipped classroom as the main means, and appropriately choose the above three teaching methods.

\section{A. Scaffolding Instruction and integrate course content}

The teaching idea of the scaffolding pedagogy based on the constructivism learning theory is derived from Vygotsky's "Nearest Neighborhood Development Zone" theory. Scaffolding teaching should provide students with a conceptual framework across the "Nearest Neighborhood Development Zone", using appropriate opportunistic situations to provide students with appropriate, small-scale hints (scaffolds) that allow students to gradually climb and gradually discover and solve learning the problem, and finally achieve it without the help of teachers to complete their own learning, by this means students' ability to solve problems and self-learning ability can be developed.

In order to cultivate students' application ability, according to the characteristics of "mechanic vibration" course with much knowledge and abstract, we follow the step-by-step teaching process of Scaffolding Instruction and integrate the content of the course with application oriented. In the limited class hour, according to the teaching idea of "simplifying the basic theory, paying attention to the simple application, strengthening the comprehensive design", the course learning task is decomposed into the following modules: the theory and application of vibration of single degree of freedom system, the theoretical basis and engineering example of vibration of two degree of freedom system, the theoretical basis of multi degree of freedom system vibration and the engineering example, the vibration of single degree of freedom nonlinear system. Meanwhile, we supplement the course project. The curriculum design is arranged at the beginning of the course to give the students a clear goal. During the course period, the progress of the inspection is irregular to urge the students to use the module design in time. After the end of the course through the reply acceptance, give students plenty of time to optimize the design and writing reports. In the theory and practice of teaching, abandon the traditional theory and experimental separation of the model, and use the theoretical and experimental teaching integration model. In the implementation process, combined with the flip classroom method, the teaching time and space extended to the pre-class and after the end of teaching. Before class, according to the stage of learning objectives, teachers design teaching projects, and provide students with video-based learning materials, that are scaffold. Students set up a study group of 3-4 people and the group as a unit to carry out pre-class self-study, exchange and discussion. In the classroom, teachers organize the group of students to review and discuss, and then sum up the main theoretical knowledge points according to the students' learning situation, and then further put forward the design requirements of the teaching project, and finally achieve the ultimate goal of the module teaching project in the experimental teaching. After the end of the course, students are required to use modular design ideas to optimize the curriculum design, which is one of the main means of testing and evaluation of the overall learning effect of the course. Each module in the course of learning, as an instructor of students' learning activities, the teacher's role should be smaller and smaller to reduce student dependence on teachers. Teaching project design is more and more comprehensive and open to enhance students' ability of autonomous learning and cultivate creative thinking ability.

\section{B. Random Access Instruction and carry out the basic part of teaching}

The basic part of the course includes the concept of vibration, classification of vibration, the establishment of mechanical model of vibration system and its differential equations, free vibration and forced vibration response, free vibration of two degrees of freedom, forced vibration, vibration equation of multi-degree of freedom system established and its matrix representation, the system eigenvalues, eigenvectors, free vibration, forced vibration response of multi-degree of freedom system; physical properties of nonlinear vibration system, equivalent linearization method, harmonic balance method, multi-scale method and approximations. In the face of a large number of professional terms, students often have "look at the bible, listen to the bible" feeling. If in accordance with the order of teaching materials, teachers teach the above basic knowledge step by step, then students can not remember some basic concepts, can not understand the terminology, can not keep up the idea of teachers, it is easy to produce displeasure. The essence of "simplifying the basic theory" is that the basic theory can be used at the beginning of the study, and the understanding of the basic theory can be deepened continuously through the application and training in the middle and later stages until it is thoroughly integrated. To this end, we have introduced the Random Access Instruction method as an application-oriented approach. Random access teaching method is Spiro and others for advanced learning, under the guidance of understanding the theory of flexibility put forward. Its core idea is that the learning of the same content should reach the goal of acquiring advanced knowledge at different times, under rearranged circumstances, with different purposes, and from different perspectives on many occasions. In theory teaching, we will take some measures:

Class theory teaching, in order to enhance students' ability of self-learning and comprehensive application of knowledge, the organization of teaching contents insisted on highlighting key and difficult points, deepening the emphasis on teaching difficulties, while some of the contents were supplemented by students' self-learning-based network discussion and counseling. According to the trends and characteristics of the development of mechanical engineering, the teachers in charge of lectures combine with their own research direction, timely update the content of teaching, expand the students' field of vision and enhance the sense of innovation. 
Symposiums and scientific reports, in addition to the traditional classroom teaching, there are also additional topics to be discussed in the online teaching platform and in the classroom. At the same time, students are encouraged to combine the topics discussed with the extra-curricular activities of the university students in science and technology, to select outstanding scientific and technical reports to be published in the classroom and to receive teachers and all students' questions. This change from the original one-way instillation teaching to the student-centered interactive teaching stimulates students' enthusiasm for autonomous learning.

Using the network platform for interaction and exchange, active use of advanced teaching methods, improve the "mechanic vibration" multimedia courseware to enhance the vivid and intuitive teaching, to deepen the students of mechanic vibration theory and understanding of key technologies. Through the online teaching platform, check online Q \& A at anytime to achieve the teacher-student interaction between students and interaction.

Open examination method, strengthen the construction of network test question bank, and pay attention to students' ability to understand the basic principles and concepts and to apply theoretical knowledge to solve practical problems. Using written examination + special report (oral test) a combination of assessment methods, focusing on examining students' overall quality and ability to innovate.

\section{Anchored Instruction for the application teaching}

The textbook of mechanical vibration tends to be theoretical. In order to improve students' interest in learning and help students understand the role of mechanical vibration theory and methods in the mechanical system, the simple application part of the course adopts the Anchored Instruction teaching method based on flipped classroom.

Anchored instruction requires students to feel and experience problems in the real environment, rather than listening to the teacher's indirect introduction and explanation. This teaching method is very suitable to emphasize the application of "mechanic vibration" course teaching.

In the experimental teaching of this course, the original teaching model based on verification type is changed to an open and research-based teaching experiment. On the basis of deepening the students' understanding of the theoretical problems of the curriculum and focusing on training students to apply what they have learned theoretical analysis and the ability to solve practical problems, provide students with space to develop their own innovative potential.

Experimental teaching content design, according to the experimental teaching requirements and objectives of "Mechanic Vibration", this paper designs the forced vibration of free-vibration and undamped two-degree-of-freedom system without damping and two-degree-of-freedom viscous damping system with viscous forced vibration of two-degree-of-freedom system dampened a total of four research projects, students choose one or two of them, to provide students with more practical space.
- Preparation before the experiment: Each student is required to select a certain engineering problem according to the knowledge and literature, reduce the engineering problem to the corresponding physical model, and transform the physical model into the mechanical model, and finish the preparation of the simulation program.

- Commissioning on the machine: the preparation of the program on the machine debugging. Analyze the experimental results, write the experiment report. And the experiment report will be made into PPT for class exchange.

- Teachers are responsible for guiding and inspiring: teachers to discuss with students before the students determine the program and to answer student's questions in time. Teachers participate in the classroom to report and discuss and comment on students' experiments.

Experimental teaching effect, this open and research-based experimental teaching model has received very good teaching results: through their own experiments on the design, summarization and analysis, students not only deepened the understanding of the basic principles of theoretical courses, but also initially learned the scientific research methods, and lay a solid foundation for future graduation thesis. Many students think this kind of open-ended experimental teaching is very interesting. It provides students with opportunities for full use of talents and creativity, stimulates students' research interest and initiative, and improves students' ability to solve practical engineering problems.

This inquiry-based learning method includes the pre-class, theory class discussion, experimental teaching and curriculum design and other aspects of large projects, students continue to grasp the application of abstract and fragmented knowledge points, improve the ability of individuals to learn and exercise their innovation thinking ability. Before class, students take the tasks related to the profession to check the information, which can help students to discover and solve problems. In the classroom to elaborate on their own learning outcomes, exercise students' written (PPT production) expression and presentation skills. In discussions with group classmates and with other groups and teachers, students' teamwork, team spirit and communication skills are cultivated.

\section{TEACHING ACHIEVEMENTS AND CHALLENGES}

On the basis of in-depth understanding of the learning situation of students, constructivism learning theory and flip class, we made a comprehensive reform of "Mechanic Vibration" course. Under the premise of not affecting the professional training plan, the teaching syllabus of the theory and experiment was revised, the teaching methods were improved, and the examination methods were reformed. Reducing the proportion of final exam scores $(70 \%$ of the total score) and increasing the score of the large program of the course (30\% of the total score) are well recognized. Students can actively participate in all aspects of teaching, and gradually formed in the teaching of "Help and in turn surpass each other" 
learning atmosphere. Under the background of innovation and entrepreneurship education, students continually optimize the design of large-scale curriculums to participate in such innovative and entrepreneurial projects as the "Challenge Cup".

In the teaching reform practice, all teachers and students have put forward new teaching requirements. As for the teacher, the teacher is changed from the "leader" in the traditional teaching to the "mentor" and "supervisor" of the student learning process. The teaching design before class, the preparation of teaching materials, the construction of the online teaching platform, answering questions to students through the internet requires a great deal of time and effort. Second, higher requirements are put forward for teachers' academic knowledge structure and the ability of using advanced information technology. Teaching project design should be close to professional, there is a certain degree of practicality and feasibility to stimulate students' interest in exploring. Video data should be fully considered in a certain period of time to ensure the integrity of knowledge. Finally, the content of the course is accomplished through extracurricular self-study, how the teacher supervises the students' learning, how to organize the class discussion and how to exert the autonomy of the students to test the communicative ability and psychological quality of teachers and students. As for the students, the students become the active agents of knowledge construction from the teaching "passive person". The learning is no longer a mixed class and should take the initiative to accept new learning methods and actively devote themselves to all aspects of teaching. First of all, students need to spend a lot of time before the class to find information, organize, discuss and summarize, in order to benefit from the class discussion. This requires students to self-management and constraints. Second, students need to be good at all aspects of teaching in order to achieve good grades in the overall program. This requires students to have the courage to accept the challenge, have a good psychological quality, with some critical and creative thinking. Finally, students need to have a degree of cooperation and communication skills in order to achieve the ultimate knowledge building.

In order to achieve excellent educational reform results, teachers and students should work together to create a positive and entertaining teaching atmosphere. Teachers should take the initiative to accept the new challenge of innovation and entrepreneurship education in the new period. How to combine the teaching of professional courses with innovation and entrepreneurship education has little experience for reference. The innovation process of teaching is the process of teachers' personal exploration and construction of new knowledge. Only when teachers have the courage to innovate teaching mode can they cultivate students with innovative consciousness. Students should also correct attitude towards learning, and strive to complete the professional learning during the university, and strive to cultivate their own innovative spirit and entrepreneurial ability.

\section{CONCLUSION}

Constructivism and flipped classroom teaching methods complement each other, they are requirements of the realization of the "student centered" teaching concept, to achieve the goal of training talents under the background of innovation and entrepreneurship education. In order to better cultivate students' comprehensive ability and innovative ability, in the future teaching reform, we will further optimize the teaching project design and implementation plan.

\section{ACKNOWLEDGMENT}

This research was supported by the project of quality curriculum construction for graduate students in Jiangxi. (Jiangxi Province teaching and research document [2016] third file ranking 14)

\section{REFERENCES}

[1] YAN Xue-yi. On Developing Students' Innovative Ability from the View of Structuralism[J]. Vocational and Technical Education, 2002, 23(28):5-8. (In Chinese)

[2] CHEN Luo, WU Ye, XIONG Wei, JING Ning. Study on the Constructivism of Teaching Method for Specialized Courses for Information [J]. Journal of Electrical \& Electronic Education, 2017, 39(1):74-78. (In Chinese)

[3] HE Ke-kang. Constructivism teaching mode, teaching method and teaching design $[\mathrm{J}]$. Journal of Beijing Normal University(Social Sciences), 1997(5):74-81. (In Chinese)

[4] Song Zhao-xia, Yu Qi-ding. Research on Project- based Teaching Model Based on Flipped Classroom [J]. Journal of Distance Education, 2014(1):96-104. (In Chinese)

[5] ZU Yun-xiao, HOU Bin,LI Wei-hai, ZAHNG Yong, ZHANG Qi. MOOC and Flipped Classroom Based on SPOC [J]. Journal of Electrical \& Electronic Education, 2016, 38(1):5-8. (In Chinese)

[6] LI Pin. College English Flipped Classroom Teaching Analysis Based on Constructivism Horizon $[\mathrm{J}]$. The Guide of Science \& Education, 2016(1z):117-118. (In Chinese) 